\title{
UNA PETICIÓN DE AYUDA AL CARDENAL GRANVELA
}

LUIS GIL

Universidad Complutense. Madrid

Para el 'simbólico' (en griego: 'a escote') convivio filológico con el que celebramos a Fernando Díaz Esteban traía yo más suculenta tajada. Rechazóseme por razones de espacio y de ahí que acuda ahora a la cita con esta minúscula porción que ni corresponde a los méritos del homenajeado, ni al afecto que le profeso. Así que, a falta de pan, buenas nos sean tortas.

Hace unos años, en el homenaje a otro insigne hebraísta, Federico Pérez Castro, el Profesor J. M. Floristán y yo hicimos una tímida incursión en la cristiandad armenia y publicamos una carta del patriarca David IV a Felipe III '. En esa misma línea saco hoy a la luz un documento anterior en más de medio siglo, que se conserva en la Biblioteca de Palacio (II-2253, fol. 217r). Se trata de una carta que el patriarca Estéfano dirige a Antonio Perrenot, señor de Granvelle, el cual en su calidad de canciller acompañaba a la sazón (1551) a Carlos V en su infructuoso viaje a Alemania y Flandes en busca de una solución al conflicto religioso. En la serie de patriarcas homónimos es este Estéfano III (que compartía por entonces esa dignidad con el katholikós Gregorio XII o con Miguel ${ }^{2}$ ), quien en

' "Las misiones luso-españolas en Persia y la cristiandad armenia", Sefarad 46 (1986), 207-218 y "Carta del patriarca armenio David IV a Felipe III", ibid. 207-218.

${ }^{2}$ Cf. Oriens Christianus, in quatuor patriarchatus digestus; quo exhibentur Ecclesiae, Patriarchae, caeterique praesules totius Orientis. Studio et opera R.P.F. Michaelis le Quien, Morino-Boloniensis, Ordinis Fratrum Praedicatorum. Opus posthumum. Tomus primus, Tres magnas complectens Dioceses Ponti, Asiae, et Thraciae Patriarchatui Constantinopolitano subjectas. Parisiis ex typographia regia. M. DCCXL, nof CXI y CXII, col. 1412. En el primero se lee: «Stephanus III. Anno 1536 Gregorius XII sedebat et anno 1541 una cum Gregorio Stephanus III". En el segundo: "In Catalogo Michaclem una cum Stephano III sedisse fertur". 
1562 envió a Pío IV un emisario ${ }^{3}$ con la propuesta de acatar la autoridad papal a cambio de recibir ayuda contra el Turco.

La guerra declarada a Persia por Solimán el Magnífico, aprovechando la discordia entre el shah Tahmasp y su hermano Elkaz Mirza que había buscado refugio en el imperio otomano (1547), ponía en serio peligro las regiones limítrofes entre ambos imperios, Georgia, Armenia, Azerbaiján, dada la táctica de tierra quemada empleada por los contendientes. Elkaz Mirza, tras dos años de operaciones con las fuerzas otomanas, se retiró a Estambul, dejando en poder del sultán un puñado de fuertes en Georgia y la fortaleza de Van, en torno a la cual se organizó una provincia como dique de contención a la penetración safávida en Anatolia ${ }^{4}$. El riesgo que corrían los armenios era evidente.

La situación de la Europa oriental permitía, por lo demás, forjarse ciertas esperanzas de ayuda. Segismundo II Augusto de Polonia (1548-1572) con el que este país llegó al zenit de su esplendor y poderío, inquieto con la propagación del protestantismo por sus dominios, se había aliado con Fernando I de Austria (2-VII-1549) poniendo fin al contencioso que había enfrentado a su padre Segismundo I con el Rey de Romanos por el dominio de Hungría. Fernando I, descontento con el tratado de paz que se había visto obligado a firmar (13-VI-1547) con Solimán por el que se reconocía la anexión de la provincia de Buda al imperio otomano y el vasallaje de Transilvania a la Sublime Puerta, se veía ahora con las manos libres para actuar.

Era principe de Transilvania Segismundo Janos, hijo de Juan Zapolya y de Isabel, hermana del rey de Polonia, pero por su corta edad ejercía las funciones de regente el obispo Martinuzzi, quien creyó asegurar su posición de poder si le permitía a Fernando I ocupar el territorio, como así lo hizo (19-VII-1551). Esta decisión, que

${ }^{3}$ En M. LE QUIEN, op. cit., $\mathrm{n}^{2}$ CXII col. 1412 se lee: “Anno autem 1562 Armenorum Catholicus Eschmiazini Michaël omnino sedebat, quo Romanae Ecclesia communionem ambivit, misso Romam Abagaro Oratore cum multis articulis, quibus suorum fidem edisserat». Este último personaje, de nombre Marco Antonio, elevó al cardenal Santa Severina en 1588 un extenso informe sobre la situación de Georgia y las campanas de Simón I de Kartli, del que se conservan dos copias en el Archivo General de Simancas, sección Estado, leg. 950, fols. 73-82 y en el Archivo del Ministerio de Asuntos Exteriores, fondo Santa Sede, caja 15, fols. 200-206

${ }^{4}$ Sobre estos hechos, vid. S. J. Shaw, History of the Ottoman Empire and Modern Turkey. Volume I: Empire of the Gazis: The Rise and Decline of the Ottoman Empire, 1280-1808, Cambridge 19855, págs. 101-106. 
en breve plazo sería fatal para su promotor y para la propia Transilvania, podía contemplarse todavía en el verano de ese año con cierto optimismo. El buen entendimiento que reinaba entonces entre la Cesárea Majestad de Carlos V, el Rey de Romanos Fernando I y Segismundo II Augusto de Polonia explica que el patriarca armenio tuviera plena fe en la eficacia de los buenos oficios de los primeros con el soberano polaco.

Un nuevo rayo de esperanza iluminaba el sombrío panorama que se cernía sobre la cristiandad oriental. El 1 de mayo de 1551, bajo el pontificado de Julio III, se habían reanudado las sesiones del Concilio de Trento, que, tras haber pasado por múltiples vicisitudes desde su inauguración con Paulo III el 13 de diciembre de 1545, se hallaban interrumpidas por el choque de intereses entre el Papado, el rey de Francia, el emperador y los potentados de Alemania e Italia. Desde la perspectiva angustiosa de la cristiandad oriental no era difícil crearse la ilusión de que un concilio ecuménico, limando las diferencias y allanando los obstáculos que impedían la unión de las iglesias, contribuyera también a la unión de los príncipes cristianos contra el imperio otomano y a la liberación de los pueblos sometidos a su yugo. Con esa ilusión está escrita esta carta. Estéfano, que trataba de conseguir una acción militar conjunta del Emperador y del Rey de Romanos contra el Turco, en ayuda de los armenios, los georgianos y los sirios maronitas, recomienda a Granvela la persona de su emisario y le pide que consiga para la suya cartas de recomendación de ambos soberanos dirigidas al rey de Polonia. Al propio tiempo le muestra su buena disposición para asistir al Concilio de Trento, en el caso de recibir la necesaria ayuda económica. La carta en cuestión dice así:

Reuerendissime in Christo Pater, Domi(n)e et Domi(n)e Colendissi(m)e, / cum veni in Poloniam, Clarissime Princeps, saepe coram Primoribus Regni illius / de vestra R(e)v(erendissi)ma Paternitate collocutus sum, declarans vniversis illam / Vestrae $R(e) v(e r e n d i s s i)-$ mae Paternitatis erga me beneuolentia(m) et humanitatem. $\mathrm{Nu}(\mathrm{n}) \mathrm{c}$

5 etiam $/ 5$ in ea confisus, ad Vestram $R(e) v($ erendissi)ma(m) $P($ aternitatem) scribo commendans praesentiu(m) ostensore(m) / meu(m) seruum, qui per me missus est ad Caesaream M(aiesta)tem et ad Regem $\operatorname{Ro}(m) a / n o r u m$, quo suae Maiestatis iunctis copiis velint auxilio esse Armenis, Georgianis / et Syrianis. Dignetur etiam intercedere pro me ad Sacras Maiestates, vt per / litteras Sacrarum Maiesta- 
$10 \mathrm{tu}(\mathrm{m})$ essem commendatus Regi Poloniae, vt me sua Maiestas $/ 10 \mathrm{de}$ suo Thesauro Regio prouideat censu annuo per hoc tempus q(uam)diu versor / in Polonia. Notum etiam factum est $\mathrm{m}$ (ih)i per Pontifices Poloniae, q(uod) Su(m)mus et / Primus Patriarcha Romanus celebrat Concilium, non Nationale solum, sed Oecu/menicu(m), et ego libenter adessem, si per cuiuspiam largitatem essem viatico / provisus; sic $\mathrm{e}(\mathrm{ni}) \mathrm{m}$ et maiores mei olim in Florentino Concilio adera(n)t, et nu(n)c $/{ }^{15}$ haeretici moderni facilius tali adunatio(n)e Ecclesiasti$\operatorname{coru}(\mathrm{m})$ reprimerentur. Ego / paratus sum ad omnia, quid mihi pẹr Vestram $R(e) v($ erendissi)mam $\mathrm{P}($ aternitatem) significatum fuerit. / Commendo me tandem V(est)rae $\mathrm{R}(\mathrm{e}) \mathrm{v}$ (erendissi)mae $\mathrm{P}$ (aternitati). Datum Leopoli Vigesima / Augusti. Anno Domini 1551

\section{Stephanus patriarcha Armenorum Manu propria exorator}

Supra alia manu exaratum: Stephani Patriarchae Armenioru(m). Leopoli Russiae 20 Aug. 1551. Cupit $\operatorname{com}(\mathrm{m})$ endari regi Poloniae vt liberalitate eius succurrat.

lin. 2 sepe 5 comendans 9 comendatus 11 caelebrat Naciơnale Ecumenicu(m) 15 heretici 16 quid michi 17 Comendo

Esta carta hace dudar de la exactitud histórica del malicioso comentario de Paolo Sarpi ' referente al antecesor de Julio II, el papa Paulo III, «il quale nel tempo que bollivano le contenzioni tra lui e l'imperatore per la traslazione del concilio a Bologna, che gli davano molto carico appresso a'popoli, con molte ceremonie ricevette un certo Stefano con nome di patriarca dell'Armenia Maggiore, con un arcivescovo e 2 vescovi venuti a riconoscerlo per vicario di Cristo, universale maestro della Chiesa, e rendergli obedienza». Por grande que fuera la desfachatez del tal Estéfano, se hace muy duro creer que, si ya había estado presente en Bolonia, pretendiera acudir a Trento, haciéndose de nuevas sobre la celebración de un concilio ecuménico, invocando por añadidura el mal precedente del florentino de 1439, en el que se aprobó sin resultado tangible alguno la unión con las iglesias armenia y griega.

\footnotetext{
${ }^{5}$ Istoria del Concilio Tridentino (ed. de C. VIVENTI, Turín 1974, pág. 619).
} 


\section{RESUMEN}

Publicación de una carta del Patriarca armenio Estéfano Perrenot, Señor de Granvelle, escrita en 1551. La cristiandad oriental espera que el Concilio de Trento, que ha reanudado sus sesiones, contribuya a la unión de los príncipes cristianos contra el imperio otomano. Estéfano trata de conseguir una acción militar conjunta del Emperador y el Rey de Romanos contra el Turco, en ayuda de los armenios, georgianos y sirios maronitas.

\section{SUMMARY}

The publication of a letter from the Armenian Patriarch Stephanus to A. Perrenot, Lord of Granvelle, written in 1551. The hope of the Oriental Christian world was that the Council of Trento, which had just resumed its sessions, would contribute to the union of the Christian Princes against the Ottoman Empire. Stephanus intends that the Emperor, together with the King of Romans, undertake a military enterprise against the Turk, to give help to the Armenians, Georgians and Maronite Sirians. 